\title{
Observations of a Western educator in Japan: a clash of cultures rather than a culture of clashes
}

Associate Professor Justin Dabner, Law School, James Cook University, Cairns, Australia; Adjunct research fellow in Business Law and Taxation, Faculty of Business and Economics, Monash University, Australia

Visiting Professor, Centre for Pacific and American Studies, Tokyo University

Justin.Dabner@jcu.edu.au 


\title{
Observations of a Western educator in Japan: a clash of cultures rather than a culture of clashes
}

\begin{abstract}
Japanese culture and society harbours particular strengths and weaknesses. These are, in turn, reflected in its institutions, including its universities.

The author is a frequent visitor to Japan and is currently the visiting professor in Australian cultural studies at Tokyo University. This paper reflects on the author's experience of Japanese universities from the perspective of someone with in excess of 20 years experience as an Australian academic.

Whilst not purposively controversial some of the observations may be uncomfortable. Some may also be naive as the author does not profess to understand the inner workings of Japan's tertiary sector. However the objective is to highlight some aspects of the system that to an outsider are in need of critical reflection.

The tertiary education system in Japan epitomises the cultural paradox: the challenge of transforming or internationalising conservative institutions steeped in tradition.
\end{abstract}




\title{
Observations of a Western educator in Japan: a clash of cultures rather than a culture of clashes
}

\author{
Associate Professor Justin Dabner, Law School, James Cook University, Cairns, Australia; \\ Adjunct research fellow in Business Law and Taxation, Faculty of Business and \\ Economics, Monash University, Australia
}

Visiting Professor, Centre for Pacific and American Studies, Tokyo University

Introduction

Law is at its most basic the study of controversy. However, as the first legal academic to be appointed to the role of Australia's cultural professor at Tokyo University, I was counseled to be wary delivering material that was too controversial - avoid a culture of clashes. Certainly the role has diplomatic overtones and there is a need to respect the system in which one is a guest. But on the other hand, Western academic orthodoxy has university as the very place best suited to discuss controversial topics and promote dialogue and change. So the proposition to refrain from addressing controversial issues is challenging. One such issue is, indeed, the very same Japanese tertiary education system.

Japan has been there many times before and it finds itself there once more - at the cross-roads or intersection. Invariably the forks that the country faces lead towards either a greater opening of the country to foreign ideas or a retreat to a more Japanese way of doing things.

The country was there in the middle of the $16^{\text {th }}$ century when it opened its doors to Western influence for the first time. ${ }^{1}$ The doors remained open long enough to secure the latest knowledge in guns-smithing before being closed abruptly in the face of the threat to social cohesiveness presented by Christianity.

The doors stayed shut, or at least only slightly ajar, ${ }^{2}$ for over 200 years until the arrival of more (black) ships ${ }^{3}$ and, with them, the realization that the country could again benefit from the injection of foreign ideas, especially technology. Unfortunately after the intense effort to modernize that then ensued the country was hijacked by militaristic forces with disastrous consequences. It could be suggested, however, that even the empire building that spawned from the Meiji restoration was a consequence of the adoption of Western ideas, this time those of the British and European colonists of the new World.

In 1945 it seemed that the doors were permanently removed from their hinges as the American occupation set about dramatically changing Japanese society. But as the American influence waned the barriers to foreign ideas gradually re-asserted themselves and the unique Japanese way of doing things again came to dominate.

Now in 2013 after decades lost in an inability to make the hard decisions that would see the scuttling of old ideas of patronage, governance, social structure, education and so on in favour of

\footnotetext{
${ }^{1}$ Traditionally, the "opening" dates back to 1543 (the "Tanegashima shipwreck").

${ }^{2}$ A small Dutch contingent was able to maintain a trading base at Dejima near Nagasaki.

${ }^{3}$ US Commodore Matthew Perry entered Tokyo Harbour with four steam ships in 1853 and demanded that Japan open up to trade.
} 
modern foreign ideals the country faces an abyss. With a population declining at World record rates $^{4}$ the eventual extinction of the Japanese race has even been mooted. ${ }^{5}$ Before then though the country's increasingly smaller workforce will ground to a halt under the pressure of a poorly funded social security system unable to bear the strain of the ageing population. ${ }^{6}$ That is if the country, with a public deficit considerably worse than that of Greece, ${ }^{7}$ does not become bankrupt first. ${ }^{8}$

Many of the cultural issues that this commentator sees as impacting on Japan's development are reflected in the educational setting. The aim of this paper is to air some observations in the hope of contributing towards the conversation on education within the country. The author does not profess to understand all the issues at play nor suggest that West is best. ${ }^{9}$ Rather the following presents some observations of "things" that to a foreign observer might benefit from critical reflection. $^{10}$

\section{The gender gap}

What is going on with the women of Japan? Of course I generalize but what is this fascination with the cute, with designer labels, with fashion generally and with cosplay in particular? Doe eyed young woman caked in makeup stomping round in ridiculously high boats with equally ridiculously short skirts (even in the middle of winter) and high pitched voices has become a national characteristic. Sure Shibuya is an extreme microcosm of the country but venture to other suburbs, cities or towns and still we see sunglasses at night, fashion glasses with no lens and the ubiquitous toy poodle equally as manicured as its owner and also dressed in the latest designer dog wear. ${ }^{11}$

It is often suggested that the young women of Japan have rebelled against the traditional role that would have seen them, once married to a salaryman, take over from the role of the doting mother

\footnotetext{
${ }^{4}$ Masumi Suga, "Japan's population falls by a record in 2012 as births decrease”, Bloomberg (1 January 2013) available at http://www.bloomberg.com/news/2013-01-01/japan-s-population-falls-by-record-in-2012-as-birthsdecrease.html (last viewed 13 March 2013).

${ }_{5}^{5}$ Michael Hoffman "Only immigration can save Japan, The Japan Times (21 October 2012) available at http://info.japantimes.co.jp/text/fl20121021x3.html (last viewed 25 February 2013) ("Hoffman 2012").

${ }^{6}$ On the implications of the population decline generally see "Into the unknown", The Economist (November 18, 2010) available at http://www.economist.com/node/17492860 and the earlier report "Japan's changing demography. Cloud, or silver linings?", The Economist (July 26, 2007) available at http://www.economist.com/node/9539825 (both last viewed 13 March 2013).

${ }^{7}$ Anthony Fensom, "Forget Europe: Is the real debt crisis in Japan?" The Diplomat (30 October 2012) available at http://thediplomat.com/2012/10/30/japan-land-of-the-rising-debt/ (last viewed 25 February 2013).

${ }^{8}$ Many other countries, in particular European countries and the United States, are on the same trajectory as Japan, or would be but for their more liberal immigration policies. It is just that Japan will arrive first.

${ }^{9}$ In fact Australian Universities are very much in decline. For a brilliant expose of the reasons why, and a warning to other countries, see Donald Meyers, Australian Universities: A portrait of decline, 2012 available at http://www.australianuniversities.id.au/Australian_Universities-A_Portrait_of_Decline.pdf (last viewed 12 March 2013).

${ }^{10}$ I owe a debt of thanks to the numerous, both foreign and Japanese, academics that I consulted with whilst preparing this paper. Many are, indeed, actively engaged in trying to confront these issues but face an enormous challenge to change highly conservative institutions.

${ }^{11}$ Generally see the observations expressed in Jeffrey Hays, "Woman in Japan: history, character, customs, advancement and violence" available at http://factsanddetails.com/japan.php?itemid=627\&catid=18 (last viewed 22 April 2013).
} 
and become housebound. ${ }^{12}$ But women's liberation appears to have taken a strange turn in Japan. The patriarchal society has found a new role for women - cute sex kittens as epitomized by the hostess clubs and maid bars. The advertising suspended from the roofs of the train carriages and the glamorization (and commoditization) of pop sensation AKB48 provides a hint at what many young women seem to be aspiring to. ${ }^{13}$ And even many of those that do depart from the hedonistic single life for matrimonial bliss see this as a chance to opt out. A 2010 survey of 568 single women released by continuing-education company U-can showed that 53.9 percent said they "would rather become a full-time housewife after marriage or childbirth" to "focus on housework or child-rearing," "spend time on their hobbies" or because "they don't like their jobs." 14

And for those woman who do make it to form the minority at Tokyo University ${ }^{15}$ a realization awaits them that they are not date worthy as young men are intimidated by them. Meanwhile their equally astute predecessors have moved onto the bureaucracy (unlikely) or corporate or universities ${ }^{16}$ but when tea and coffee is delivered to the committee meetings who do you think is expected to pour it? ${ }^{17}$

The World Economic Forum's 2012 global gender gap report ${ }^{18}$ places Japan at $101^{\text {st }}$ place worse than many Muslim nations including Malaysia $\left(100^{\text {th }}\right)$ and Indonesia $\left(97^{\text {th }}\right)$. Yet this is a first world democracy with a solid rule of law. Women who remonstrate for equal treatment will not be doused in fuel and set alight or have acid thrown in their faces. The country is failing to capitalize on a major resource ${ }^{19}$ yet much of the female population seems complicit in this failing.

It is time to discard the cosplay outfit! Let us see more women aspire to Tokyo University and from there to serious careers!

\footnotetext{
${ }^{12}$ Merry White, "Home truths: women and social change in Japan" (1992) 121(4) Daedalus 61- 82.

${ }^{13}$ For one instance of the AKB48 sensation see: Patrick St Michel and Daisuke Kikuchi, “AKB48 'election' shows marketing brilliance" The Japan Times (31 May 2012) available at

http://www.japantimes.co.jp/culture/2012/05/31/music/akb48-election-shows-marketing-brilliance/ (last viewed 25 February 2013). Also see Greg Scott, "Attack of the AKB48 clones", Japanese Blog (28 December 2012) available at http://japanese.lingualift.com/blog/akb48-clones/ (last viewed 25 February 2013).

${ }^{14}$ Tomoko Otake, "Japanese women strive to empower themselves" The Japan Times (3 March 2013) available at http://www.japantimes.co.jp/life/2013/03/03/people/japanese-women-strive-to-empower-themselves/\#at_pco=cfd-

1.0 (last viewed 3 March 2013) ("Otake"). There is even a Japanese expression for such women ("Sanshoku hirune tsuki") that translates as: "three meals and a nap".

${ }^{15}$ Yuki Iida, "The male to female ratio in the University of Tokyo" The Komaba Times (4 December 2012) available at http://komabatimes.wordpress.com/2012/12/04/female-ratio/ (last viewed 27 May 2013).

${ }^{16}$ Women researchers count as a mere $13.8 \%$ of the University population: Otake.

${ }^{17}$ And if they have a child and wish to return to the workforce on a flexible or part-time basis then they can expect to be re-employed at the bottom of the ladder: Jeff Kingston, "Saving Japan: promoting women's role in the workforce would help" The Japan Times ( 21 April 2013) available at http://www.japantimes.co.jp/opinion/2013/04/21/commentary/saving-japan-promoting-womens-role-in-theworkforce-would-help/ (last viewed 27 May 2013).

${ }_{18}$ http://www.weforum.org/issues/global-gender-gap (last viewed 21 February 2013).

19 The issues and opportunity is discussed in Jeff Kingston, “Saving Japan: promoting women's role in the workforce would help" The Japan Times (21 April 2013) available at http://www.japantimes.co.jp/opinion/2013/04/21/commentary/saving-japan-promoting-womens-role-in-theworkforce-would-help/\#at_pco=cfd-1.0 (last viewed 22 April 2013).
} 


\section{Internationalization}

To say that Japan is a mono-culture is no exaggeration. With only around $1.7 \%$ of the population born outside the country, and most of these folks Korean or Chinese, readily recognizable foreigners are a rarity indeed. ${ }^{20} 400,000$ or so non-Asian faces (excluding tourists) are soon lost in a population of 128 million. For a visitor from a country, where in excess of $27 \%$ of the population was born elsewhere, ${ }^{21}$ this truly is the greatest point of distinction. But let me make an aside here. After much deliberation I do not believe that immigration and the pursuit of a multi-cultural society is a must do for Japan. The Australian experiment is unique. In the absence of an all prevailing pre-existing culture steeped in tradition other cultures have been able to more readily carve a niche for themselves within the fabric of Australian society. Not so easy for a foreign culture trying to integrate into Japan with its complex language, protocols, traditions and nuances, even one with Japanese heritage like the Nikkei Burajiru-jin, as the dekasegi experience illustrates. $^{22}$ The solution to Japan's declining population and associated economic malaise may, alternatively, lie in greater automation and robotics as some suggest. ${ }^{23}$ The country needs to have this debate about its future - maybe a smaller, materially poorer yet spiritually and environmentally richer Japan is achievable.

No foreigner needs any reminder that they are aliens in a strange land. Those who have mastered the language, or at least know what the word gaijin means, are well aware that they are outsiders who are fingerprinted on entry, must at all times carry their residency cards, are often discriminated against and for whom citizenship awaits after a long ten years of permanent residency. ${ }^{24}$ Statistics reveal that most foreigners do not stay the course and move on from Japan after a few years. ${ }^{25}$

One feels that there are competing forces in the society. On one hand, there is clearly an attempt to make life easier for foreigners. In the 12 years I have been travelling here the country has become much more user friendly for a non-native with more signs, websites and pamphlets in English. ${ }^{26}$ On the other hand, the bureaucracy associated with other than a tourist visa remains intimidating and, as I understand it, often overwhelming. ${ }^{27}$

\footnotetext{
${ }^{20}$ Hoffman 2012. Also see the Statistics Bureau of Japan website and details of the 2010 census available at http://www.stat.go.jp/english/data/kokusei/index.htm (last viewed 13 March 2013). The Bureau provides statistics on registered foreigner residents. It is not clear how second and third generation Koreans, for example, born in Japan but not citizens are regarded. In any event, however the figures are compiled the point is that foreign residents, especially non-Asians, are a rarity.

${ }^{21}$ Australian Yearbook 2012 available at http://www.abs.gov.au/ausstats/abs@.nsf/Lookup/by\%20Subject/1301.0 2012 Main\%20Features Country\%20of\% 20birth 54 (last viewed 25 February 2013).

22 See Greg Scott, "Dekasegi: Japan's abandoned people”, Japanese Blog (21 March 2012) available at http://japanese.lingualift.com/blog/dekasegi/ (last viewed 25 February 2013).

${ }^{23}$ Hoffman 2012.

${ }^{24}$ Five years if you are lucky enough to marry a local.

${ }^{25}$ Debito Arudou, “Japan's revolving-door immigration policy hard wired to fail” The Japan Times (6 March 2012) available at http://www.japantimes.co.jp/community/2012/03/06/issues/japans-revolving-door-immigration-policyhard-wired-to-fail/ (last viewed 25 February 2013). ("Arudou 2012")

${ }^{26}$ Or, at least, a form of English. The term "Japenglish" has been coined to refer to the unusual translations that often appear on signs in the country which a web search on Google images will quickly illustrate.

${ }^{27}$ Ibid. Also see John W Traphagen, “Japan's demographic disaster” The Diplomat (3 February 2013) available at http://thediplomat.com/2013/02/03/japans-demographic-disaster/ (last viewed 13 March 2013).
} 
Japanese universities seem to reflect this ambiguity. Whilst the Government has its Global 30 project designed to lead to an international academic environment, ${ }^{28}$ the impression of many foreign academics I speak to is that whilst the desire to "internationalize" is often professed, identifying exactly what this means and how to achieve it remains elusive. At a forum of foreign staff of Tokyo University in late 2012 the hierarchy asked these very questions. One professor, with over two decades of service to the University, spoke of how the University had been talking of "internationalizing" the whole time he had been there. At least the forum was a new development although the message that was reiterated of the need to provide more foreign (primarily English) language subjects, employ more foreign academics (not just to teach English language) and researchers, reconcile the academic calendar with that of the northern hemisphere, and generally make the University more foreigner friendly presents a much greater challenge. ${ }^{29}$

\section{The deadman's handle - sleep deprivation and the pursuit of the material}

Board any train at any time of the day and you would be forgiven for thinking that the Japanese people have a national obsession with "cat naps". The ability of these nappers to be able to wake up just as the train arrives at their station is quite remarkable, although stories of dozing passengers repeatedly circling the Yamanote loop have been related to me. ${ }^{30}$

But "cat naps" are not reserved for train trips. I attempt to be an enthusiastic teacher and engage with my students. Video clips, exhibits, role playing, group discussions, group breakouts, even physical activities are a feature of my classes in response to the claims of the teaching and learning specialists that concentration spans of Generation Y mandate that presentation methods should be changed after no more than seven minutes. So I was devastated to experience, notwithstanding these techniques, Japanese students nodding off to sleep in my classes.

After summonsing the courage to ask my colleagues of their experience (in fear of the embarrassing revelation that it was just me) I was relieved to hear that this was a universal phenomenon - plaguing schools and even workplaces. So I went back to my students to ask why and was met with the explanation that most students sleep only four to five hours a night, apparently reflective of much of the population. I am led to believe that this norm of sleep deprivation starts in the high school years when students are cramming in anticipation of those all important entrance exams. But it is not merely study keeping students from their sleep but many (most?) have one or two jobs as well.

A similar phenomenon is occurring in the West (although without the nodding off element maybe sleep deprived Australian students simply do not come to class). The explanation touted is that students need to earn income to survive. This has always been the case but what I have noticed over the years is that students appear increasingly better off. Designer clothes, late model cars and (of course) smart phones and laptops are much more a feature of university campuses

\footnotetext{
${ }^{28}$ Discussed in Kazuaki Nagata "Universities to boost classes in English" The Japan Times (15 March 2013) available at $\quad$ http://www.japantimes.co.jp/news/2013/03/14/national/universities-to-boost-classes-inenglish/\#at_pco=cfd-1.0 (last viewed 15 March 2013).

${ }^{29}$ It has been reported that some Universities are to focus on these very steps. However one concern is that foreign academics will be employed on a casual or part-time basis and, therefore, unable to make much of the impact: ibid, and see the comments online.

${ }^{30}$ Hence the reference to the "deadman's handle" a device used in trains (and other mechanical devices) which stops the engine running if the handle is released, as would occur should the driver fall sleep. Given the predisposition of the passengers to fall asleep I often wonder if Japanese train drivers are similarly conditioned.
} 
these days than in the past. My suspicion is that we have spawned a material obsessed generation who need to work, not merely to survive, but in order to afford their iphone fix.

And this brings me back to Japan and this time the obsession with shopping, especially for designer labels. What is it with (European) luxury goods? Japan is the most profitable market in the World for Louis Vuitton ${ }^{31}$ and, I suspect, Veuve Clicquot. These products do not come cheap - in fact their primary appeal is the status their expense conjures - but, of course, there are also many home grown commodities that can soon burn up your Yen. Maybe Ginza does not quite have the same shine as a decade ago ${ }^{32}$ but there are plenty of expensive omiyage shops with their expensive fruit, cookies, mochi, chocolates, etc, etc.

So a simplistic suggestion might be less shopping and more sleeping! But on a more serious note if the suggestion that the student population is surviving on so little sleep is accurate then the causes of this need to be investigated. This is not conducive to a good health let alone a good learning outcome.

\section{The nail that sticks out ${ }^{33}$}

One of the prominent themes in comparative cultural studies between Japan and the West is the difference in emphasis placed on the importance of the group versus the individual. Japanese culture, it is suggested, elevates the interests of the group over the individual. This is embodied in various sayings and protocols which still resonate in $21^{\text {st }}$ century Japan. In stark contrast, in Australia for example, individuality is championed as an admirable national trait.

For the Western educator in Japan attempting to import Western pedagogical techniques, especially elements of Socratic teaching, this cultural background presents a challenge. In one soul destroying class I presented early on at Chuo University I summonsed every technique I knew to elicit engagement from the students but failed abysmally to achieve more than a slight murmur from the class during my 90 minutes of slow death.

Having experimented and adapted my techniques since I have discovered that a better method than seeking answers or comment from individual students is to break the class into small groups who each appoint a spokesperson to report on the group's view on an issue. It is intriguing to occasionally hear the emphasis in the spokesperson's report on that they are merely stating their group's opinion to which they may neither agree nor disagree.

Of course much of the reluctance of student's to speak out can, understandably, be in appreciation of, or embarrassment with, their English language skills. Also the preparedness of Western (Australian) students to engage in class should not be overstated. Whilst our Generation $\mathrm{Y}$ is characterized as brash and confident, this confidence can readily evaporate when pressured in a classroom scenario. Furthermore, some of the most dynamic and engaged students I have encountered have been Japanese students studying in Australia.

\footnotetext{
31 "Losing its shine" The Economist (18 September 2008) available at http://www.economist.com/node/12270950 (last viewed 25 February 2013).

32 Ibid.

${ }^{33}$ From the Japanese Deru kugi wa utareru that translates as "The nail that sticks out is struck down", a traditional Japanese proverb preaching against standing out from the group.
} 
My conclusion is, therefore, that encouraging students to engage more in their learning is very much related to their educational experiences. Where they have been brought up in a "chalk and talk" environment where the educator is God and there is little opportunity for a student to comment or ask questions (or it is even considered disrespectful), students will retreat into their note taking. Upon subsequently encountering an unfamiliar environment where they are expected to engage they will, naturally, be challenged.

\section{Meetings, forms and more meetings}

The Japanese people's work ethic is legendary. Long hours are the norm. But there is a suspicion that this is necessary to make up for a lack of productivity and efficiency.

Furthermore, there seems to be strange ambiguity operating in Japan. In a country that was forced into World leadership in robotics in the 1960s to combat workforce shortages there are many people performing jobs of very questionable value. How many shopping attendants do you really need when most are standing around doing little more than joining the chorus of "irasshaimase"? There seems to this observer to be a plethora of crossing guards, traffic control personnel and other attendants, most of whom could readily be replaced by mechanical devices if needed at all. In short, there seems to be a lot of hidden or institutionalized unemployment work of questionable value.

Which brings me back to universities. Japanese professors, without exception it seems, are a harried lot. But it is not just research or maybe even teaching that seems to be taking up all their time, but rather administration and endless meetings. Every Western academic I have spoken with in this country on this topic has related the same observation - probably reflecting a grave fear that institutions in our own countries may be heading the same way.

Furthermore, there seems to be a vast number of university employees engaged in administrative matters but what many of them actually do has eluded me. Possibly they are engaged in the seemingly endless production of forms and compliance with procedure. Certainly there seems to be numerous opportunities for efficiency gains.

Professors I have spoken with, both Japanese and Western, joke of the need to employ all these administrators as the contribution by the universities to keep the unemployment rate down. Is there really a civic plan to try and ensure that everyone has a job no matter how menial? As for the meetings that drag on in pursuit of consensus, is this reflective of the group culture and the reluctance to be the one making the decision? I do not know but it does seem to me that many university procedures and decision making structures should be reviewed with a view to letting the academics get on with what they are renowned for (and some sleep).

\section{Entrance exams and University rankings}

All universities around the World have an eye to both their domestic and international rankings. There is no doubt, whether rightly or wrongly, that if you are a graduate form a highly ranked institution your career path (at least initially) is likely to be enhanced.

In Japan, though, this phenomenon has reached heights that see high school students study obscene hours in an attempt to score well in their entrance exams, enter one of the more 
prestigious universities and then set themselves up for life. ${ }^{34}$ Ironically once they have secured that sought after enrolment the pressure subsides. It is understood that the award of a failure at University is not an option (except in extreme cases) so the students can coast through their top university experience before joining the bureaucracy or large company and commencing the age determined career trajectory. ${ }^{35}$

It must be queried whether such a system is both healthy and achieves the best outcome for the individual and, indeed, for society. A system that places a little less pressure on the individual during their difficult adolescent years and a little more on them whilst at university, together with merit based appointment and promotion, would seem preferable in my view.

As a final observation on University education, a debate should occur as to whether the system of possibly studying twenty odd subjects is optimal. Coupled with the negligible failure rate this inevitably leads to a shallow learning outcome with little expectation of the students undertaking additional studies outside of class. In turn this adds to the internationalization dilemma. Cross crediting of subjects between foreign universities is problematic in both directions. ${ }^{36}$

\section{But all is not bad}

Being constantly drawn back to this country I am often asked why - especially by Japanese friends and acquaintances. There are many attractions - the people, the culture, the food, the history. Above all though there is the quaintness - the sense of difference. Each visit I learn and understand a little more but I remain overwhelmingly perplexed as to how this society operates and what motivates its people.

From what I have gathered though, without doubt, respect for the group and authority stands out to me as the most impressive national trait. This characteristic is reflected in the very low crime rate, lack of vandalism, care for public assets and general cleanliness. Where in the West could you have vending machines, some selling alcohol and cigarettes, in a public space and not expect them to be vandalized and their contents stolen? Yet I have never heard of such a thing here.

Whilst an obsession with staring at you smart phone whilst striding through a station and expecting others to move out of the way is a rising trait and misuse of the yusen seki (priority seats on trains) is a common phenomenon these indiscretions are counterbalanced by the increasing custom of the wearing a face mask by those who are unwell with a view to not infect others. ${ }^{37}$ How amazingly considerate! Whilst some older Japanese people may suggest that the younger generation lacks respect, every other society in the World should envy Japan for the

\footnotetext{
${ }^{34}$ John Spacey, “What happens when you fail University entrance exams in Japan?” Japan Talk (1 August 2012) available at http://www.japan-talk.com/jt/new/ronin-students-in-Japan (last viewed 25 February 2013).

35 The same seems true of bottom institutions: Nicolas Gattig, "Failing students: Japanese universities facing reckoning or reform" The Japan Times (13 November 2012) available at

http://www.japantimes.co.jp/community/2012/11/13/issues/failing-students-japanese-universities-facing-reckoningor-reform/ (last viewed 25 February 2013).

${ }^{36}$ Unfortunately this is only one of the issues facing returning Japanese students who have studied overseas. Japanese companies typically have quite inflexible HR programs and so a student who has not embarked on a mainstream Japanese tertiary education may find it difficult to find employment: Chris Burgess, "Ambivalent Japan turns on its 'insular' youth" The Japan Times (21 May 2013) available at http://www.japantimes.co.jp/community/2013/05/21/issues/ambivalent-japan-turns-on-its-insular-youth/ (last viewed 27 May 2013).

37 And, for some, so as to reduce the chances of catching a cold.
} 
level of domestic security, peace, politeness and general consideration for the interests of others enjoyed and demonstrated by its people.

Allied to this national characteristic is the sense of community that seems to exist, even in the big cities. To me, Japanese suburbs and towns have a nostalgic feeling - the Australia of my childhood. The little corner stores, the old folk wandering around and sitting on park benches, the families playing in parks, the pushbikes, the quiet narrow roads, the young children walking home from school or outside playing, the feeling of security - all these features combine to create a sense of community that has so waned in my country and, I suspect much of Western society. Pockets of nostalgia may exist in some parts of mainly, regional, Australia but this remains a widespread phenomenon in Japan. And then the music plays at $5 \mathrm{pm}^{38}$ and it is time for all to return home for a hot bath and dinner!

\section{Conclusion}

Entrenched traditions are difficult for any society to break away from. However, the Japanese character for change is 変 (hen / $k a$ ) which also means strange or unusual. Perhaps, that says it all.

My time in Japan has enforced in me the view that the opposite of any words that might be used to describe the part of the Western World where I come from and its people, Australia and Australians, could be attributed to a description of Japan and the Japanese: spacious/crowded, casual/formal, indifference towards authority/respect for authority, celebration of individuality/obedience to the group, boisterous/reserved, multi-culture/mono-culture, searching for national identity/steeped in tradition and so on. But, at the same time, the relationship between the two countries and their people bears out the notion that "opposites attract". Cultural conviviality is alive.

On the flip side our differences mean that there is much that we can learn from each other. I hope that this paper is a contribution towards that end.

\footnotetext{
${ }^{38}$ Music is broadcast on speakers throughout Japan at 5pm.
} 